\title{
PARATHYROID ADENOMA: PRESENTED WITH GENERALIZED BONE PAIN AND MULTIPLE PATHOLOGICAL FRACTURES IN A 29 YRS LADY- A CASE REPORT
}

\author{
OSMANY HQ ${ }^{1}$, BEGUM A² ${ }^{2}$ FAKIR MAY ${ }^{3}$, LITON MA ${ }^{4}$, CHOWDHURY MFI $^{5}$
}

\begin{abstract}
:
One of the common reasons of primary hyperparathyroidism is parathyroid adenoma. This can present in different ways- diffuse bone pain, multiple stones in the body warranting repeated surgery, renal failure, abdominal discomfort, depressed mood etc. Here we present a young women presented with surgical removal of gall stone and renal stones, pathological fractures and her generalized bodyache was treated for rheumatological cause for a long time. After surgical removal of adenoma he got back to life within couple of months.
\end{abstract}

Key words: Primary hyperparathyroidism, multiple stones, parathyroid adenoma

J Dhaka Med Coll. 2017; 26(1) : 83-85

\section{Introduction:}

Symptomatic Primary Hyperparathyroidism (PHPT) can present in various ways- with skeletal involvement (bone pain, fracture and palpable multiple Osteitis Fibrosa Cystica (OFC) being the major clinical symptoms. Besides, renal calculi with nephocalcinosis and renal failure, fatigue with proximal muscle weakness, pancreatitis, gall bladder stone, constipation and depression can be presenting complaints. Hence the clinical manifestations are coined with the following terms kidney stones, abdominal goans, painful bones psychic moans and fatigue overtones. Here we present a young lady suffering from her age of 22 years and diagnosed at 29 years of age, with a misery of 7 years.

\section{Case Report:}

A 29-year-old married women presented with pain in the multiple joints of upper and lower limbs for last 7 years. She was treated with different analgesic with a presumptive diagnosis of rheumatoid arthritis. Along with this she was also having abdominal discomfort and constipation for the same period. Five years back she developed upper abdominal pain and was treated with PPI, assuming peptic ulceration as she was taking NSAID for a long time. Later it was diagnosed as gall bladder stone and was operated. After one year she again developed loin pain and this time diagnosed as bilateral renal stone and right stone was removed. But her generalized bone pain was continuing. For last 5 months she was bed ridden and unable to walk. Xray hip showed pathological fracture of left hip and was admitted in the Medicine Department of Dhaka Medical College Hospital. Upon enquiry she gave history of passage of stone with urine on several occasions, but denies of any morning stiffness. On examination she was ill looking, with diffuse tenderness all over body, no joint swelling, wasting of muscles of both upper and lower limb. Her left hip movement was restricted and painful. BP-100/80 mm of $\mathrm{Hg}$, pulse- $88 / \mathrm{min}$. Examination of neck- normal, no swelling or nodule palpable. A diagnosis of

1. Dr. Husne Qumer Osmany, Assistant Professor, Department of Otolaryngology and Head Neck Surgery, Dhaka Medical College

2. Dr. Afrina Begum, Associate Professor, Department of Obstetrics and Gynecology, Dhaka Medical College

3. Dr. Md. Abu Yusf Fakir, Professor, Department of Otolaryngology and Head Neck Surgery, Dhaka Medical College

4. Dr. Md. Assaduzzaman Liton, Assistant Registrar, Department of Otolaryngology and Head Neck Surgery, Dhaka Medical College Hospital

5. Dr. Faizul Islam Chowdhury, Professor, Department of Medicine, Dhaka Medical College

Correspondence : Dr. Husne Qumer Osmany, Assistant Professor, Department of Oolaryngology and Head-Neck Surgery, Dhaka Medical College, Dhaka

Received: 17 December 2016

Accepted: 01 March 2017 
Primary Hyperparathyroidsm was made with the findings of S. Calcium- $12.8 \mathrm{mg} / \mathrm{dl}, \mathrm{PTH}-$ $1770 \mathrm{pg} / \mathrm{dl}$ (range-15-60 pg/dl), S. Inorganic phosphate- $1.9 \mathrm{mg} / \mathrm{dl}$, USG neck- enlarged left lower parathyroid $\left(3.1 \mathrm{X} 1.1 \mathrm{~cm}^{2}\right)$. Radiological evaluation shows multiple fractures: impacted pathological fracture of right neck of the femur (Fig-1), osteopenia with fracture of upper end of right humerus (Fig. 2) and fracture of right $6^{\text {th }}$ rib. Localization of parathyroid was done by

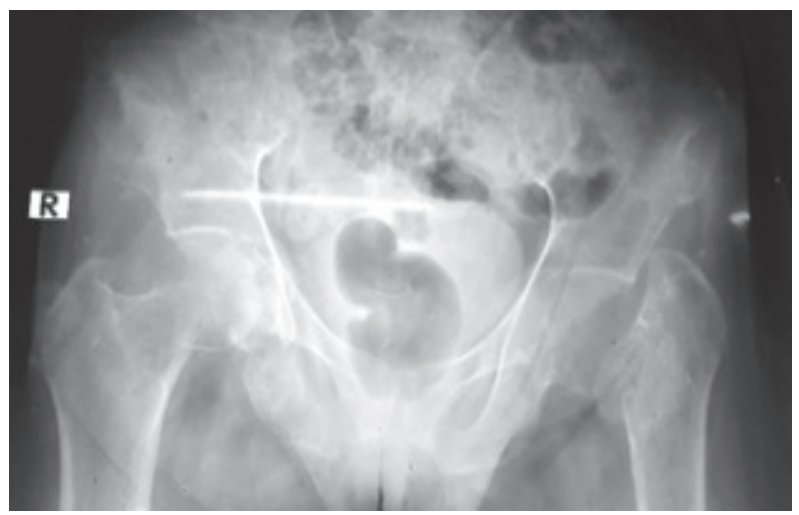

Fig.-1: Impacted pathological fracture of left femur

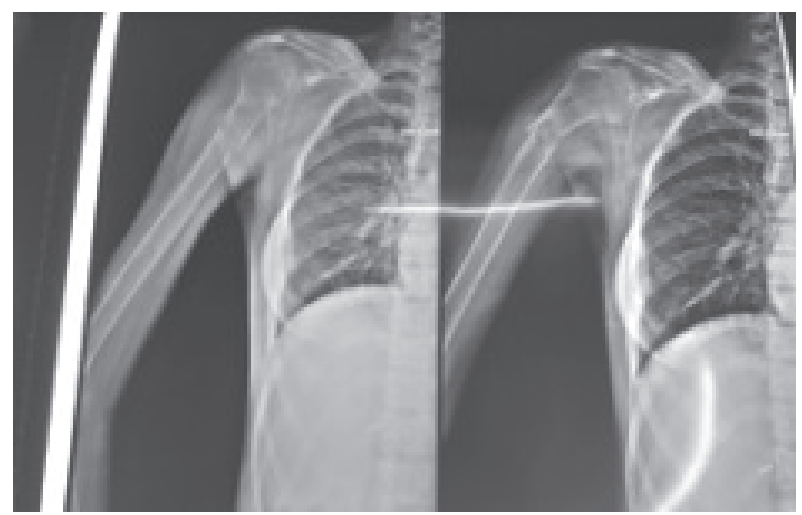

Fig.-2: Fracture of upper end of humerus

sestamibi scan with thallium-technetium subtrac-tion study/ technetium - 99 m (Tc - 99 $\mathrm{m})$ and uptake was visible on both early and delayed film (Fig.3). Other investigations: thyroid function tests, S. Creatinine, S. Uric acid, RA test, RBS, S. uric acid and CBC were within normal limit. Surgery was done through neck incision and the adenoma is removed in total (Fig. 4). Immediately after surgical removal of the adenoma a rapid reduction of PTH to $5.44 \mathrm{pg} / \mathrm{dl}$ was noted. Patient was given IV Calcium after operation for 2 consecutive days followed by oral Calcium for 10 days. Serum

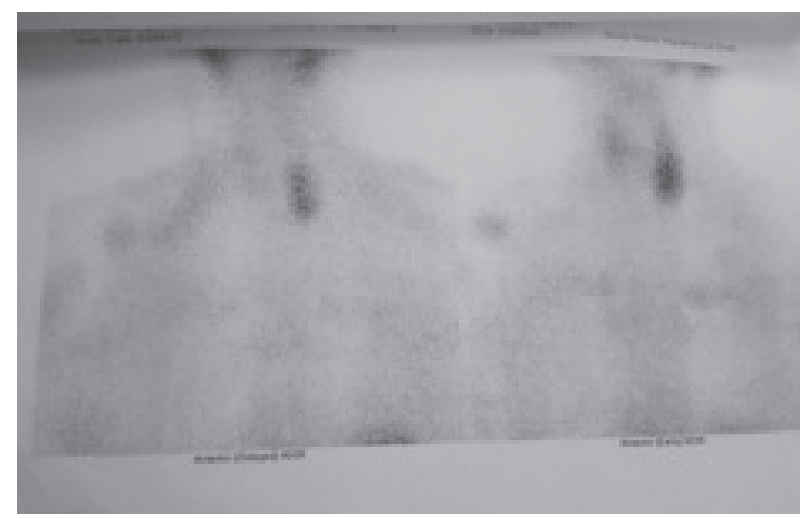

Fig.-3: Parathyroid Adenoma located by sestamibi scan (Early and delayed uptake)

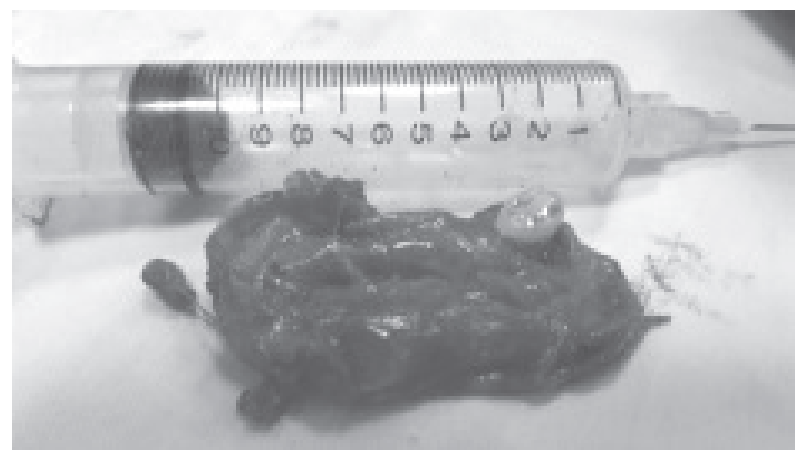

Fig.-4: Parathyroid adenoma after removal

calcium level was stable at $9.82 \mathrm{mg} / \mathrm{dl}$ during post-perative period. Histopathology showed parathyroid adenoma. No tetany or tingling of face was observed. Patient was followed up over next 8 months and was having normal life with no pain and appearance of new fractures.

\section{Discussion:}

Our patient was presented at earlier age $(22$ yrs), Indian study showed far younger age (2155 yrs) group than western data ${ }^{1}$. Several case reports from Bangladesh age ranges from 18$64 \mathrm{yrs}^{2}$. Diagnosis in the western world diagnosis is mostly of asymptomatic cases through routine screening for other problems. In a study of 97 cases from US, radiological evidence of bone disease was only $1 \%$ and nepholitiasis was found in $18 \%$ cases $^{3}$. But study from this sub-continent showed most of the cases diagnosed are symptomatic cases. In a study with 37 cases operated with primary hyperparathyroidism, over 12 years period in Aga Khan University of Pakistan, showed 32.4\% with bone disease alone and $27 \%$ with both 
bone and stone diseases ${ }^{4}$. Our patient presented with both bone and stone disease, presentation of bone pain was due to osteopedia and multiple fractures. Lag period for diagnosis was found to be 1 month to 16 years in North India ${ }^{5}$. Our case was diagnosed after 7 years (84 months). She could have been diagnosed earlier when presented with multiple stone diseases, repeated passage of stones with urine and body ache but no signs of rheumatoid arthritis. Besides these she also had constipation and proximal muscular weakness which are also a feature of Hyperparathyroidism. PHPT can also present with abdominal pain $(39 \%)$, polyuria $(37 \%)$, psychiatric manifestations (23.1\%) and palpable neck nodule in $19 \%$ v. Our patient had abdominal pain most probably from cholecsytitis from stone disease and had no neck nodule. Surgery is curable in almost all cases and parameters for successful surgical exploration is normalization of corrected parathormone and calcium levels. In this case parathormone and S. Calcium both came normal after surgery. With the availability of sestamibi scan parathyroid can be localized in most of the cases $(91 \%)$ and USG can detect in $78 \%$ cases $^{6}$, eased removal of the gland during surgery. We operated through neck incision, endoscopic parathyroidecotomy of two cases with three ports has been reported from surgery Department of BSMMU ${ }^{7}$.Our patient had her normal life back after removal of the adenoma. Otolaryngology Department of BSMMU has reported 32 cases over 7 years period (20002007) with mostly with bone and stone disease $^{8}$.

In our department we also operated 6 cases over last 2 years (2014 to 2016) presented mainly with bone and stones disease. High index of suspicion with a good surgical team can alleviate longer misery of hyperparathyroid cases.

\section{Conclusion:}

Delay in the etiological diagnosis of primary hyperparathyroidism can cause misery in the life of patient. S/he may undergo different modalities of treatment for a longer period of time. Our case has undergone multiple surgeries, different medical treatment over a period of 7 years before the definitive treatment. High index of suspicion can reach early diagnosis and give patient early relief for physical and financial pain.

\section{References:}

1. Gopal RA, Acharya SV, Bandgar T, Menon PS, Dalvi AN, Shah NS. Clinical profile of primary hyperparathyroidism from western India: A single center experience. Journal of Postgraduate Medicine; 2010, 56(2): 79-84.

2. Khan MK, Taous A, Sultana SZ, Sharif A, Hossain MM, Mostafa G, Hussain MA, Azim MA, Siddique MA. Neck swelling with renal stone. Mymensingh Med J. 2010 Oct;19(4):622-6.

3. Bilezikian JP, Silverberg SJ, Shane E, Parisien M, Dempster DW.J Bone Miner Res. Characterization and evaluation of asymptomatic primary hyperparathyroidism. 1991;6 Supp1 2:S85-9

4. Biyabani SRJ, Talati J.Bone and renal stone disease in patients operated for primary hyperparathyroidism in Pakistan: is the pattern of disease different from the west?J Pak Med Assoc. 1999;49(8):194-8.

5. Bhansali A, Masoodi SR, Reddy KS, Behera A, das Radotra B, Mittal BR, Katariya RN, Dash RJ. Primary hyperparathyroidism in north India: a description of 52 cases.Ann Saudi Med. 2005;25(1):29-35.

6. Khaliq T, Khawar A, Shah SA, Mehboob A, Farooqui A. Unilateral Exploration of Primary Hyperparathyroidism. J Coll Physician Surg, Pakistan, 2003;13(10):588-91

7. Aziz MM, Khan AW, Uddin MF, Hasanat MA, Kader MA, Chowdhury AJ, Choudhury NA.Endoscopic para-thyroidectomy: a new approach. Mymensingh Med J. 2010 Jul;19(3):442-6.

8. Razib FA, Mannan M, Biswas AK, Al-Amin Z, Ahsan AI, Dey BK, Wahiduzzaman M, Kamal MA, Islam MT.Presentation of primary hyper-parathyroidism due to adenoma. Mymensingh Med J. 2013 Apr;22(2):320-4. 